Review Article

\title{
Mechanism of Inflammation in Age-Related Macular Degeneration: An Up-to-Date on Genetic Landmarks
}

\section{Francesco Parmeggiani, ${ }^{1}$ Francesco S. Sorrentino, ${ }^{1}$ Mario R. Romano, ${ }^{2,3}$ Ciro Costagliola, ${ }^{3}$ Francesco Semeraro, ${ }^{4}$ Carlo Incorvaia, ${ }^{1}$ Sergio D'Angelo, ${ }^{1}$ Paolo Perri, ${ }^{1}$ Katia De Nadai, ${ }^{1,5}$ Elia Bonomo Roversi, ${ }^{6}$ Paola Franceschelli, ${ }^{6}$ Adolfo Sebastiani, ${ }^{1}$ and Michele Rubini ${ }^{6}$}

\author{
${ }^{1}$ Department of Biomedical and Specialty Surgical Sciences, Ophthalmology Unit, University of Ferrara, \\ Corso Giovecca 203, 44121 Ferrara, Italy \\ ${ }^{2}$ Department of Ophthalmology, Istituto Clinico Humanitas, Milan, Italy \\ ${ }^{3}$ Department of Health Sciences, University of Molise, Campobasso, Italy \\ ${ }^{4}$ Department of Ophthalmology, University of Brescia, Brescia, Italy \\ ${ }^{5}$ Center for Retinitis Pigmentosa of Veneto Region, ULSS 15 Alta Padovana, Camposampiero, Italy \\ ${ }^{6}$ Department of Biomedical and Specialty Surgical Sciences, Medical Genetic Unit, University of Ferrara, Ferrara, Italy
}

Correspondence should be addressed to Francesco Parmeggiani; francesco.parmeggiani@unife.it

Received 23 July 2013; Accepted 28 September 2013

Academic Editor: John Christoforidis

Copyright ( $) 2013$ Francesco Parmeggiani et al. This is an open access article distributed under the Creative Commons Attribution License, which permits unrestricted use, distribution, and reproduction in any medium, provided the original work is properly cited.

\begin{abstract}
Age-related macular degeneration (AMD) is the most common cause of irreversible visual impairment among people over 50 years of age, accounting for up to $50 \%$ of all cases of legal blindness in Western countries. Although the aging represents the main determinant of AMD, it must be considered a multifaceted disease caused by interactions among environmental risk factors and genetic backgrounds. Mounting evidence and/or arguments document the crucial role of inflammation and immune-mediated processes in the pathogenesis of AMD. Proinflammatory effects secondary to chronic inflammation (e.g., alternative complement activation) and heterogeneous types of oxidative stress (e.g., impaired cholesterol homeostasis) can result in degenerative damages at the level of crucial macular structures, that is photoreceptors, retinal pigment epithelium, and Bruch's membrane. In the most recent years, the association of AMD with genes, directly or indirectly, involved in immunoinflammatory pathways is increasingly becoming an essential core for AMD knowledge. Starting from the key basic-research notions detectable at the root of AMD pathogenesis, the present up-to-date paper reviews the best-known and/or the most attractive genetic findings linked to the mechanisms of inflammation of this complex disease.
\end{abstract}

\section{Introduction}

Age-related macular degeneration (AMD) is the leading cause of irreversible central vision loss in elderly populations in developed countries, and 30-50 million people are affected worldwide. In the United States, it has been estimated that the prevalence of AMD is $13.4 \%$ among persons aged 60 years and older $[1,2]$. AMD affects all retinal layers of the macula, the structure responsible for the central vision involving, in different degenerative patterns, photoreceptors, retinal pigment epithelium (RPE), and Bruch's membrane. AMD is primary characterized by the development of drusen, pathological extracellular deposits between RPE and Bruch's membrane mainly containing glycolipids, proteins, and cellular debris. At the level of macular area, the presence of few small hard drusen can be considered as a part of the normal tissue aging. On the other hand, AMD consists of numerous and large soft drusen, RPE dystrophy, macular pigmentary changes, and/or thickening of Bruch's membrane [3-8]. Advanced AMD can manifest as either dry form or wet one. In dry AMD, geographic atrophy with RPE and photoreceptors degenerative changes occurs. Conversely, wet AMD is characterized by the presence of choroidal neovascularization $(\mathrm{CNV})$ with exudative and 
hemorrhagic phenomena leading to fibrotic scar formation [8-11].

Susceptibility to develop AMD is influenced by a number of genetic and environmental factors [12]. AMD is in fact considered a multifactorial disease, caused by the interplay between multiple acquired factors and polygenic background. Recent epidemiological data have identified numerous risk factors as potential modulators of AMD; aging, cigarette smoking, previous cataract surgery, and family history of AMD show strong associations with the disease, whereas higher body mass index, history of cardiovascular disease, hypertension, and higher plasma fibrinogen result in moderate AMD's risk [13]. Although family history is a wellknown risk factor for AMD, it is not a routine practice to alert those with a family history to the increased risk and advise them of the relevance of recognizing early symptoms. An accurate quantification of risk associated with a family history of AMD has been reported in the UK population [14]. This study confirmed that family history is a strong risk element for AMD, highlighting the importance of genetic factors in the pathogenesis of AMD. Individuals with an affected sibling or an affected parent were reported to have a 12 -fold increase in the odds of disease. Odds ratio (ORs) adjusted for age and smoking were even higher: $23 \%$ of siblings resulted to be affected by CNV or geographic atrophy with an OR of 10.8, which increased to 16.1 adjusting it for patient's age. Similar figure was previously reported in two large population-based studies, the Rotterdam Eye Study [15] and the Beaver Dam Eye Study [16]. The first reported an OR of 14.3, showing that the risk of AMD increased to 19.8 if smoking was taken into account. The latter study resulted in an OR of 10.3, which probably was underestimated, as the study relied on at least one sibling being free of disease at baseline and the sibships where all siblings were affected by AMD were excluded; when only randomly selected sibships were included, the OR was 26. Other studies reported family history of AMD being associated with lower ORs, but that could be attributed to the inclusion of cases with less severe disease [17-20]. A recent UK study has documented that the onset of disease was earlier in cases who had AMD affected siblings than in those without. This is typical for a complex disease with a substantial genetic component, for which the onset of disease is at a younger age in those with a family history [14].

Numerous genomic regions and a variety of candidate genes have also been seen to impact AMD susceptibility. Although strong associations between genetic factors and AMD have been illustrated, it is likely that a significant part of the heritability of AMD cannot be explained through current known mechanisms [21-23]. A number of genetic variants have been associated with AMD, and a recent genome-wide association study (GWAS) has provided significant $(P<$ $5 \times 10^{-8}$ ) evidence of nineteen AMD susceptibility loci [24]. Meta-analyses of GWASs for AMD estimated that currently identified loci account for approximately $60-70 \%$ of the inherited predisposition to clinically significant AMD forms [24-27]. The hugely mounting number of scientific reports regarding AMD-related gene variants counteracts the chance to get any unequivocal interpretation of these correlative data.
In this complex scenario, which has built up more than ever in the last five years, several genes seem to be the most attractive in playing remarkable roles in different steps of AMD pathogenesis [24-37].

In the present review, we will focus on the best-known gene variants involved in the immunoinflammatory pathogenesis of AMD, particularly considering the regulation of both complement activity and cholesterol homeostasis.

\section{Complement Activity}

The complement system is one of the main components of the innate immune response and fulfils numerous functions, such as the recognition of foreign cells, communication with and activation of adaptive immunity, and the removal of cellular debris. Complement consists of over 40 proteins and cells, comprising a well-balanced network of circulating and cell-surface-bound proteins, which serve as substrates, enzymes, or modulators of a hierarchical series of extracellular proteolytic cascades. There are three well-known mechanisms of complement activation: classical, lectin, and alternative pathways. Each pathway is activated by different stimuli and the initial steps that trigger the complement activation differ considerably. The final stage of the enzymatic cascade of events is the lysis of bacteria or viruses and the opsonization, which consists in a sort of marking cells or molecules to be removed by the host [38-40].

The classical pathway is stimulated by the recognition of antigen-antibody complexes on foreign-cell surfaces by the hexameric complement component Clq. Similar pattern-recognition receptors, that is mannose-binding lectin (MBL) and ficolins, bind to carbohydrate ligands on microbial intruders and initiate the lectin pathway. Conversely, the alternative pathway is stimulated by the spontaneous hydrolysis of native $\mathrm{C} 3$ or the presence of foreign surface structures. Recent findings suggest that additional processes, such as the C2-bypass and extrinsic protease pathways or properdin-mediated direct convertase assembled on microbial surfaces, can also initiate complement activation [41-43].

All of the complement cascades end up in the central cleavage of $\mathrm{C} 3$ and in the generation of its active fragments $\mathrm{C} 3 \mathrm{a}$ and C3b. Opsonization of foreign surfaces by covalently attached C3b fulfils three major functions:

(i) cell clearance by phagocytosis;

(ii) amplification of complement activation by the formation of a surface-bound C 3 convertase;

(iii) assemblage of the $\mathrm{C} 5$ convertase.

Cleavage of $\mathrm{C} 5$ results in the formation of a multiprotein pore complex (MAC, membrane-attack complex), which leads to cell lysis. Both the covalent attachment of $\mathrm{C} 3 \mathrm{~b}$ and the stabilization of $\mathrm{C} 3$ convertase by the complement regulator properdin are markedly activated by hydroxylrich pathogen surfaces. A number of complement receptors mediate the recognition of opsonized cells by leukocytes, which induces phagocytosis and stimulation of the adaptive immune system (B and T cells). Finally, the anaphylatoxins 
C3a and $\mathrm{C} 5 \mathrm{a}$ are released during complement activation and trigger a range of chemotactic and proinflammatory responses, such as recruitment of inflammatory cells and increase of microvasculature permeability. In this way, the complement cascade also supports and promotes the function of downstream mechanisms of the immune response $[44,45]$.

Detrimental effects take place in case of exaggerated complement activation on self tissue. In addition to a locationbased and time-based restriction to immediate sites of activation, a finely tuned set of soluble and membrane-bound regulators ensure that any overstated action of complement on host cells is either prevented or actively inhibited. There is a large number of regulators of complement activation, including complement receptor 1 (CR1), complement factor $\mathrm{H}(\mathrm{CFH})$, factor $\mathrm{H}$-like protein-1 (FHL-1), C4-binding protein $(\mathrm{C} 4 \mathrm{BP})$, decay-accelerating factor (DAF), and membrane cofactor protein (MCP) [46].

Complement is the most important pathogenic pathway of the immune system involved in AMD [8, 47-53], clearly indicating that complement activation is implicated in its pathogenesis [54-58]. Although AMD is not a classic inflammatory disease, immunocompetent cells, such as macrophages and lymphocytes, are present in chorioretinal tissues with AMD $[59,60]$. Specific alteration and/or dysregulation of innate immune system are observed in AMD eyes mainly at the level of complement pathway elements, such as complement components C3a and C5a, C5 and C5b9 terminal complement complex, complement regulators or inhibitors (i.e., CFH, vitronectin, and clusterin), CR1, MCP, and DAF, but also at the level of C-reactive protein [61-68]. Activation products C3a, C5a, and C5b-9 are also systemically elevated in patients suffering from AMD [69-72]. Due to genetic evidence from GWAS as well as from common and rare variant analyses, the overactive alternative pathway has been investigated showing that its excessive engagement is a key component in AMD pathogenesis [24-37, 54-58, 7377]. During AMD, several immunopathological phenomena occur within the structures of the macular area, especially due to the pathophysiologic effects of complement system, which have a main role in the parainflammation of the aging retina $[8,47-53]$. In particular, reliably because the posterior retinal layers (i.e., photoreceptor outer segment, RPE, and Bruch's membrane) are more prone to environmental and/or bloodcirculating oxidative stresses [78-82], they epigenetically represent the preordained site of onset of the elementary AMD lesions (drusen) [3-8]. In fact, unregulated choroidal blood flow may increase the fluctuations of oxygen and/or lipids concentration, leading to elevated generation of reactive oxygen species (ROS) [80-82]. Likewise, photooxidation in photoreceptors is associated with complement activation, which can increase MAC formation, an important trigger of those apoptotic processes inducing retinal degeneration [83-86]. In this pathogenetic context, the critical position of complement must be emphasized. In fact, exactly complement's dysregulation can lead to that autologous damage which, at macular level, provokes the development of drusen: the earliest hallmarks of AMD acting as foci of chronic inflammation [8, 49-53].

\section{Cholesterol Homeostasis}

Recent investigation array has highlighted that neural retina and RPE express most of the genes involved in cholesterol homeostasis [87]. Indeed, it has been reported that retina can synthesize cholesterol endogenously $[88,89]$ and express proteins mediating cholesterol transport [90-92] and removal [93-95]. At the present time, detection of several cholesterolrelated genes suggests that cholesterol homeostasis in the retina might be considered relatively independent of the rest of the human body. Taking part, respectively, in internal and external blood-retina barriers, endothelial cells of neural retina (NR) and RPE cells synthesize and acquire cholesterol from low- and high-density lipoproteins (LDL and HDL) derived from blood circulation. However, the ratio between blood-borne cholesterol and endogenously synthesized is not well-known yet $[87,96,97]$.

A large interindividual variability of cholesterol and lipoprotein metabolisms is unquestionable, but it is intriguing the fact that RPE has higher variations in expression of cholesterol-related genes than NR. It could be accounted for a sort of "gate-keeping" function of RPE controlling cholesterol and nutrient uptake from blood-stream to NR and reverse transport of metabolites from NR back to systemic circulation. At RPE level this gene expression is promptly modulated in response to fluctuations of blood lipids. Moreover, this adjustment varies in each individual depending on blood lipid profile, age, gender, lifestyle, and genetic background. There are a lot of fine mechanisms of regulation pertaining to cholesterol-related genes in both NR and RPE but, despite the many experimental findings, most of them are not currently well known [87]. At NR level, it seems that photoreceptor outer segment (OS) deals with intraretinal cholesterol transport by means of active and passive mechanisms [98]. The active transport of cholesterol from photoreceptor inner segment (IS) to the OS partially occurs via intracellular cholesterol transporter NiemannPick C1-like 1 [99-101]. Another modality of cholesterol mobilization involves scavenger receptors, especially that named scavenger receptor Class B Member 1, which mediates bidirectional cholesterol flux between cells and lipoproteins; in this manner, the photoreceptor OS can uptake lipids from the HDL-like particles and offload lipids to the same particles as well [102-107]. Regarding the passive mechanism, it is known that photoreceptor IS lies in a high-cholesterol environment than OS; hence, IS can provide cholesterol for OS just through passive diffusion. Because of loss of efficiency in either some of these systems or phagocytosis, the cholesterol accumulates in the basal OS disks dampening down the phototransduction cascade [106, 108, 109].

In the retina, the RPE plays a key role in cholesterol homeostasis controlling both cholesterol input and output $[110,111]$. Experimental findings have indicated the presence of different pathways, even if the cholesterol offload via apolipoprotein B-mediated transport is regarded as one of the main mechanisms involved in AMD pathogenesis. In fact, with aging, the apolipoprotein B-containing particles pool in the Bruch's membrane forming esterified and unesterified cholesterol-enriched lipid deposits named drusen. Very little 
is known about AMD and dysregulation of cholesterolrelated genes, but it might be assumed that several affected individuals can be carrier of specific metabolic impairments in proteins determining cholesterol uptake (e.g., 3-hydroxy3-methylglutaryl-CoA reductase and low-density lipoprotein receptor) and/or in those mediating cholesterol removal (e.g., ATP binding cassette transporter $1-A B C A 1-$ cytochromes P450) [91, 92]. Although further investigation is needed to better elucidate these clinicogenetic relationships, recent GWAS identified four HDL-related genes as remarkable risk factors for AMD: LIPC (hepatic lipase), CETP (cholesteryl ester transfer protein), $A B C A 1$, and $L P L$ (lipoprotein lipase) $[25,31,32]$.

In several age-related vascular disorders, increased levels of oxysterols play a crucial role provoking atherosclerosis with subsequent local and chronic inflammation. Homeostasis of cholesterol in blood vessel wall is of essential importance to regulate circulating cholesterol levels. A key event in the development of atherosclerosis is the uncontrolled uptake of oxidized LDL by macrophages recruited in the subendothelial space. The aberrant increasing of these lipidloaded macrophages, termed foam cells, becomes a crucial condition causative of highly local inflammation [112-117].

Focusing on the lipoprotein retention in vascular wall, a parallel between atherosclerotic disease and AMD is identifiable. In atherosclerosis, apolipoproteins B cross the arterial endothelium, bind to proteoglycans, undergo oxidative and nonoxidative processes, and trigger downstream events, such as foam cells build-up and cytokine release [112, 118, 119]. In AMD, lipoprotein-like particles (enriched with esterified cholesterol) accumulate in the Bruch's membrane, especially in the space between the RPE basal lamina and the inner collagenous layer, forming lesions able to trigger inflammation, complement activation, and cytotoxicity (i.e., lipidrich lesions, basal linear deposits and, finally, drusen) [3$8,91,92,120-122]$. RPE physiologically plays a critical role in the uptake, processing, and offload of retinal lipids. It uptakes the most part of oxidized lipoproteins via scavenger receptor Class B Member 3 and LDL receptors from the blood circulation, but it is also able to synthesize lipoproteins endogenously. On the other hand, aged or stressed RPE is unable to properly process the oxidized lipids, when the macrophages, which normally clean up these deposits, become less efficient and are slowly intoxicated by excessive levels of 7-ketocholesterol (7KCh) and other oxidized lipids [87-89, 96, 97, 123]. 7kCh is an oxidized form of cholesterol, that is, an oxysterol formed by auto-oxidation of cholesterol and cholesterol esters [124-127]; it is found in oxidized LDL deposits in the form of oxysteryl esters, covalently bound to oxidized unsaturated fatty acids [128-130]. Cholesteryl esters are particularly susceptible to oxidation and the cholesterol molecules in these esters can be oxidized to $7 \mathrm{kCh}$ [131-133]. In the primate retina, two main mechanisms for oxidation of cholesterol to $7 \mathrm{kCh}$ have been described: the Fenton reaction and the photooxidation [134-136]. The Fenton reaction requires a transition metal catalyst, such as iron and copper. Although the levels of these metals have not been measured in oxidized lipoprotein deposits, atherosclerotic plaques are known to contain relatively high levels of them [137]. By means of photooxidation and in presence of an adequate photosensitizer, cholesterol can be converted in a series of hydroperoxide intermediates that can further oxidize to $7 \mathrm{kCh}$. Lipofuscin fluorophore A2E is one of the well-known photosensitizers, being involved in cholesterol ROS-mediated oxidation and also in the inhibition of the normal cholesterol efflux from RPE cells [138140]. During the histopathologic evaluation of eyes affected by AMD, Lakkaraju and co-workers have documented that A2E induces aberrant cholesterol metabolism in RPE [140], which could contribute to AMD onset or progression also by means of inflammatory mechanisms.

\section{Gene Variants Associated with AMD}

Since 2005, several common variants in genes complement pathway have been consistently associated with the development of AMD. The common coding variant p.Tyr402His in the gene encoding complement factor $\mathrm{H}(\mathrm{CFH})$ was the first identified [64, 141-143]. A number of other polymorphisms in $\mathrm{CFH}$ [144], as well as in other genes involved in the alternative complement cascade, have also been demonstrated to affect AMD risk, including genes for complement component 2 (C2), complement component 3 (C3), and complement factor I (CFI) [29, 144-147]. More recently, common variants in genes encoding for cholesterol-related pathway, such as LIPC and tissue inhibitor of metalloproteinase 3 (TIMP3), have been reported to be associated with AMD in large GWASs $[31,32]$. In the next subheadings, the genes implicated in phenotypic expression of AMD will be detailed, especially considering those main contributory variants at the basis of that immunoinflammatory dysregulation which, in AMD patients, can be labeled as inflammaging [148].

4.1. Complement Factor $H$. Originally known as $\beta-1 \mathrm{H}$ globulin, $\mathrm{CFH}$ is a serum glycoprotein that regulates the function of the alternative complement pathway in fluid phase and on cellular surfaces. The binding of $\mathrm{CFH}$ to $\mathrm{C} 3 \mathrm{~b}$ reduces complement $\mathrm{C} 3$ activation, inhibits the formation of $\mathrm{C} 3 \mathrm{a}$, and lowers the production of IL-6 [149]. Besides, CFH accelerates the decay of the alternative pathway convertase $\mathrm{C} 3 \mathrm{bBb}$, and also acts as a cofactor for CFI, another C3b inhibitor [150, 151]. The $\mathrm{CFH}$ gene is located on chromosome 1q32, spans $94 \mathrm{~kb}$, and comprises 23 exons. The $C F H$ gene is located within a cluster of genes encoding the regulatory complement components of the activation of $\mathrm{C} 3$. This gene cluster includes the factor H-related genes FHR1, FHR2, FHR3, FHR4, and FHR5 and the decay-accelerating factor, C4-binding protein (C4BPA and $C 4 B P B)$, among others.

The c.1277 T-to- $\mathrm{C}$ transition in exon 9 of $\mathrm{CFH}$ gene (rs1061170) results in a substitution of histidine for tyrosine at codon 402 of the CFH protein (p.Tyr402His). This missense variant is located in the Short Consensus Repeat 7 (SCR7) that acts as a binding site of $\mathrm{CFH}$ to $\mathrm{C}$-reactive protein (CRP) and heparin [152]. The binding of CFH to CRP or heparin increases $\mathrm{CFH}$ affinity for $\mathrm{C} 3 \mathrm{~b}$ and downregulates complement activity [153]. The p.Tyr402His can be 
considered to be a functional protein variant, as the p.His 402 allele impairs the binding of CFH to CRP, thus resulting in an enhanced complement activation and consequent tissue damage. At sites of tissue injury, the p.His402 variant does not dampen the alternative pathway of complement activation as efficiently as p.Tyr402 allele [154-158]. In Caucasian populations of European ancestry the p.His402 allele is very common, having a gene frequency in the range of 0.3-0.4. The p.His402 allele is likely replacing the major one because in early life it provides a survival advantage against streptococcal infections; for example, microbes bind CFH to their surface to inhibit complement activation $[46,159]$. The CFH binding protein of group A beta hemolytic streptococcus has a lower affinity for p.His402 than for p.Tyr402. As a result, the host's complement system has greater activity against the pathogen if the host expresses p.His402, thereby reducing the microbes' ability to counteract the alternative pathway. $\mathrm{CFH}$ adheres to damaged eukaryotic cells and tissue debris via the same anionic (heparin) binding sites that microorganisms employ to attach it to their surface [160-162]. If on one hand the p.His402 allele is potentially giving some benefit, on the other hand it is one of the most significant known genetic contributor to AMD disease risk. In individuals bearing a p.His402/His402 homozygous genotype, the risk of developing all categories of AMD was estimated to be 3 -fold increased. Higher odds ratio (OR) values, in the range of 3.57.4, were found if only advanced dry and wet forms of AMD were considered $[64,141-143]$. The association between the p.His402/His402 genotype and AMD could be explained by a reduced capacity of the p.His 402 variant of CFH to bind debris in a damaged retina. Differential binding of p.His402 versus p.Tyr402 to multiple constituents of a damaged retina has been demonstrated for DNA, RNA, lipids, CRP, necrotic and apoptotic cells, heparin and other glycosaminoglycans, lipofuscin, bis-retinoids, photooxidation byproducts, and amyloid beta. The common finding is that the p.His 402 protein binds with a lower affinity than p.Tyr402. Therefore, in the retina of a p.His402/His402 homozygous individual there is a higher level of alternative pathway activation, leading to retinal debris accumulation and ultimately AMD development.

Recent evidence has been reported supporting the existence of multiple AMD susceptible alleles in the chromosome region of the CFH gene [163]. A case-control study of 84 single nucleotide polymorphisms located in a $123 \mathrm{~kb}$ genomic region in 1q32 including the $C F H$ gene provided evidence that multiple $\mathrm{CFH}$ haplotypes associate with AMD risk independently from p.Tyr402His [143]. Functional variants within these haplotypes are likely to influence the expression of $\mathrm{CFH}$ gene and possibly also of other nearby genes of the C3activation cluster. In particular, an A-to-G variant located in intron 14 of CFH gene (rs1410996) has been reported to associate with AMD [144]. In the recent GWAS of Fritsche and co-workers [24], the most strongly AMD-associated single nucleotide polymorphism in the CFH region-rs10737680was not in disequilibrium with p.Tyr402His, which instead was tagged by a weaker signal. This evidence further supports the hypothesis that multiple functional gene variants in the $\mathrm{CFH}$ locus act as risk factors for AMD.
4.2. $C 2 / C F B$ Cluster. The $C 2$ gene encodes for the complement component 2 , spans $18 \mathrm{~kb}$, and includes 18 exons. The $C 2$ gene maps in 6p21.33 and is adjacent to the CFB gene, which encodes for complement factor $B$, from which is separated by just 271 nucleotides. Common variants within the $C 2 / C F B$ cluster have been recently confirmed as being significantly associated with risk of developing AMD [164].

A missense G-to-C variant in exon 7 of C2 (rs9332739) has a frequency of 0.067 among Europeans and causes the replacement of the glutamic acid residue at codon 318 with an aspartic acid one (p.Glu318Asp). The C-to-A substitution within intron 10 of C2 (rs547154) has a frequency of 0.062 among Europeans. Minor alleles of both rs9332739 and rs547154 have a protective effect and reduce by half the risk for developing AMD. A recent meta-analysis estimated that OR of C-allele of rs 9332739 was 0.55 (95\% confidence interval (CI): $0.46,0.65$ ), while minor allele at rs547154 carried an OR of 0.47 (95\% CI: $0.39,0.57$ ) [27].

The CFB:c.26 T-to-A transversion (rs4151667) in exon 1 of $C F B$ results in the substitution at codon 9 of leucine with histidine (p.Leu9His) that has a frequency of 0.067 among Europeans. A second missense variant in $C F B$ gene, the CFB:c.95 G-to-A transition (rs641153), is located in exon 2 and determines a substitution of arginine at position 32 with a glutamine residue (p.Arg32Gln). The minor A-allele of CFB:c.26 T-to-A and the A-allele of CFB:c.95 G-to-A carried estimated risks of 0.54 (95\% CI:0.45, 0.64) and 0.41 (95\% CI:0.34, 0.51), respectively [27].

Haplotype analyses using two independent cohorts of AMD patients identified a statistically significant common risk haplotype and two protective haplotypes [145]. Both the haplotype including minor alleles of C2:c.954 G-to-C and CFB:c.26 T-to-A (H10 haplotype) and the haplotype including A-allele of rs547154 variant in intron 10 of $\mathrm{C} 2$ and the A-allele of CFB:c.95 G-to-A (H7 haplotype) confer a significantly reduced risk for AMD [145]. The protective effect of $\mathrm{H} 7$ haplotype has been confirmed in independent studies, and evidence has been reported suggesting that minor alleles of both variants contribute independently to the protective effect. To date it is not clear if the rs 547154 variant in intron 10 of $\mathrm{C} 2$ has a functional activity or rather is in disequilibrium with a causal variant, but it is likely that its minor allele could be associated with a lower expression of $\mathrm{C} 2$. The $\mathrm{CFB}$ protein containing glutamine at position 32 has been reported to reduce hemolytic activity compared with the arginine containing form and to cause less efficient complement activation $[165,166]$. This lower complement response determined by H7 haplotype could possibly explain the protective effect on AMD development. Combined analyses of the $C 2 / C F B$ haplotypes and $C F H$ variants showed that variation in the two loci can predict the clinical outcome in $74 \%$ of the affected individuals and $56 \%$ of the controls [167].

4.3. Complement Component 3. The C3 gene encodes the complement component 3 , a factor that plays important biological roles in the classical, alternative, and lectin activation pathways. The $C 3$ gene spans $41 \mathrm{~kb}$ on chromosome 9p13.3 and comprises 41 exons. The active C3 factor includes 
an $\alpha$-chain, encoded by the last 26 exons, and a $\beta$-chain, encoded by the first 16 exons, having exon 16 encoding both $\alpha$ and $\beta$-chain. The synthesis of C3 factor is induced during acute inflammation. C3 is produced mainly by liver but also by activated monocytes and macrophages. Mature C3 factor is obtained from the cleavage of a single chain $200 \mathrm{kDa}$ precursor into the $\alpha(\mathrm{C} 3 \alpha)$ and $\beta(\mathrm{C} 3 \beta)$ subunits that are linked by disulfide bonds. $\mathrm{C} 3$ factor has a critical role in the complement system, and C3 deficiency makes people more susceptible to bacterial infection. The c.304 Cto-G substitution in exon 3 of C3 gene (rs2230199) is a common missense variant that causes replacement of arginine residue at codon 102 with a glycine one (p.Arg102Gly). These two alleles correspond to the slow and fast electrophoretic variants of $\mathrm{C} 3$ factor. The p.Gly102 allele has a frequency of 0.175 among Europeans and is carried by more than $30 \%$ of individuals. Association between p.Arg102Gly and AMD has been confirmed in many studies on Caucasian populations [55, 146, 147, 164, 168, 169], but not in Asian populations, probably due to the lower frequency of the p.Gly102 allele [170]. Among Europeans, the OR for AMD has been reported to be 1.7 in p.Arg102/Gly102 heterozygotes and 2.6 in p.Gly102/Gly102 homozygotes, and the estimated population attributable risk for p.Gly102 was 22\% [147].

4.4. Complement Factor I. The complement factor I (CFI) gene maps on chromosome 4q25, spans $63 \mathrm{~kb}$, and comprises 13 exons. The first eight exons encode the heavy chain of CFI, while the light chain of CFI is encoded by the last five exons. The two chains are linked by disulfide bonds. CFI is a serine protease that plays a role in the complement pathway as it cleaves and inactivates $\mathrm{C} 4 \mathrm{~b}$ and $\mathrm{C} 3 \mathrm{~b}$. A C-to-T transition (rs10033900) located $4.3 \mathrm{~kb}$ downstream the $3^{\prime}$ UTR of CFI gene has been shown to be independently associated with AMD $[29,31]$. This variant could have a role in influencing CFI expression level or be in linkage disequilibrium with a functional regulatory variant.

4.5. ARMS2/HTRA1 Locus. A locus in 10q26.13 (LOC387715) has been identified as the second most important locus in the etiology of AMD $[170,171]$. This locus includes the agerelated maculopathy susceptibility (ARMS2) gene and the gene encoding for the high-temperature requirement factor A of serine peptidase 1 (HTRAl). A G-to-T transversion in exon 1 of ARMS2 (rs10490924) is a common missense variant that replaces an alanine residue with a serine (p.Ala69Ser). The p.Ser69/Ser69 homozygotes were reported to have a significant 7.6-fold increased risk of developing AMD [171], and this association has been next confirmed in independent case-control studies. Only $4.2 \mathrm{~kb}$ separate ARMS2 gene from the near HTRA1 gene, and the ARMS2:p.Ala69Ser variant is located just $6.3 \mathrm{~kb}$ from a G-to-A variant in the promoter region of HTRA1 gene (rs11200638). These two variants are in strong linkage disequilibrium $\left(r^{2}=0.90\right)$, and it is difficult to determine which one could be the causal variant in this locus [24]. Therefore, it is still under debate to definitively establish which gene, ARMS2, HTRA1 or possibly also others, is responsible for the genetic association with AMD [8].
The HTRA1 gene encodes a member of the trypsin family of serine proteases. The HTRAl protein is a $50 \mathrm{kDa}$ secreted enzyme that cleaves substrates involved in the complement pathway, such as clusterin, vitronectin and fibromodulin, and could theoretically play a role in the pathogenesis of AMD. The G-to-A substitution in the promoter region of HTRA1 has been initially considered a functional variant as it is located in a conserved $\mathrm{CpG}$ island and resides within a putative binding site for the transcription factor adaptorrelated protein complex- $2 \alpha$ and could possibly regulate the expression level of HTRA1 $[172,173]$. However, later studies showed that this variant does not affect the transcription level of HTRA1 in several cell lines [174] nor alters HTRA1 mRNA or protein expression in human retina-RPE-choroid samples [175]. Therefore, it is unlikely that rs11200638 is the functional variant that accounts for the strong association between the ARMS2/HTRA1 locus and the risk of developing AMD.

ARMS2 is a small gene-just $2.7 \mathrm{~kb}$ wide-that includes only two exons and a single intron. The encoded 107-amino acid peptide is expressed in the outer membrane of mitochondria and in the citosol. The p.Ala69Ser variant could affect the conformation of protein and eventually modify mitochondria function [174]. A second variant, an insertion/deletion (indel) polymorphism in the 3-prime untranslated region ( $\left.3^{\prime} \mathrm{UTR}\right)$ of ARMS2 (ARMS2:c.372_815del443ins54), has been strongly associated with risk of developing $\operatorname{AMD}\left(P=4.1 \times 10^{-9}\right)$ [164]. The association between del443ins54 indel and AMD has been replicated in different populations [176]. This indel variant removes the polyadenylation signal in the $3^{\prime}$ UTR of ARMS2 and replaces it with a $54 \mathrm{bp}$ element known to mediate rapid mRNA turnover. The expression of ARMS2 transcript is lost in homozygous carriers of the del443ins54 indel. This variant is located between ARMS2:c.269 G-to$\mathrm{T}$ and HTRA1:c.-625 A-to-G, and the haplotype including minor alleles (T-indel-A) was reported to be associated with a significant 3-fold increased risk for AMD [176]. Considering the deleterious effect of del443ins54 indel to the expression of ARMS2 transcript, we could suggest that this indel polymorphism could be the actual variant causing the increased risk of AMD associated with the ARMS2/HTRA1 locus.

The actual function of ARMS2 protein is unknown, but it is thought to play a role in diseases in the elderly [8]. ARMS2 transcripts have been detected in retina and in a variety of other tissues and cell lines [174], and it has been proposed that ARMS2 could play a key role in AMD through mitochondrial-related pathways [164]. So far, very little is known about the function of ARMS2, and more investigations are needed to determine if variants in this gene have causal role in the pathogenesis of AMD.

4.6. Tissue Inhibitor of Metalloproteinase 3. The tissue inhibitor of metalloproteinase 3 (TIMP3) gene belongs to a family of genes encoding for inhibitors of matrix metalloproteinases, a group of zinc-binding endopeptidases involved in the degradation of the extracellular matrix. TIMP3 is also a potent angiogenesis inhibitor, as it blocks the binding of VEGF to VEGFR2 and inhibits downstream signaling leading to VEGF-mediated angiogenesis [177]. The TIMP3 
gene spans $55 \mathrm{~kb}$ on chromosome 22q12.3 and includes 5 exons. TIMP3 mutations are causing a Mendelian early onset form of macular degeneration often complicated by CNV, known as Sorsby's fundus dystrophy (MIM \#136900). TIMP3 has been considered a putative candidate for AMD susceptibility, but early studies failed to find association between TIMP3 and AMD [178, 179]. Recent evidence has been reported indicating that an A-to-C substitution located far upstream (113 kb) of TIMP3 gene (rs9621532) within an intron of the synapsin III gene (SYN3) is associated with a reduced risk of developing AMD [31]. This variant influences the expression of TIMP3 transcripts in cultured primary human fetal RPE cells, and the protective C-allele of rs9621532 was associated with mRNA expression [180]. However, the genetic association between rs9621532 and AMD has not been confirmed in Asian population, and the role of TIMP3 in AMD etiology still remains controversial [181].

4.7. Hepatic Lipase. LIPC, a novel AMD gene, is involved in HDL cholesterol metabolism. The gene spans $60 \mathrm{~kb}$ on chromosome 15q21.3, includes 9 exons, and encodes a hepatic triglyceride lipase which is expressed in liver. LIPC enzyme is also a triglyceride hydrolase and a ligand/bridging factor for receptor-mediated lipoprotein uptake. Rare deficiencies of LIPC are associated with pathologic levels of circulating lipoprotein. Expression of LIPC in the retina has been reported [167]. Two variants in LIPC putative promoter, an A-to-G substitution (rs493258) located $14 \mathrm{~kb}$ from LIPC transcription start site and a C-to-T substitution (rs10468017) $22 \mathrm{~kb}$ upstream of LIPC, were reported to be associated with advanced AMD in two independent European cohorts, indicating that common variants in LIPC gene could play a role as genetic risk factor for AMD $[31,32,182]$. These variants are thought to regulate the expression of LIPC and therefore influence the metabolism of HDL cholesterol. The T-allele of rs10468017 has been reported to have a protective effect for advanced wet and dry AMD by influencing LIPC expression in serum and increasing HDL levels [32].

\section{Final Remarks}

This etiogenotypic excursus has been first and foremost aimed to speculatively interconnect two different types of gene polymorphism, which are able to alter either complement or cholesterol pathway and, consequently, to predispose to AMD via inflammation and parainflammation. Several clinicogenetic studies show increased OR to develop AMD in individuals carrying more risk genotypes [167, 183]. In particular, the carriers of combination of peculiar $\mathrm{CFH}$, $A R M S 2 / H R T A 1$, and C2/CFB genotypes have been reported to have high OR values, although significance level of these findings were relatively low, mainly due to the low number of patients included in the investigations. Calculating a risk score including genetic information across the nineteen top loci resulting from a very recent GWAS [24], Fritsche and coworkers reported that a multiple combination of genotypes could distinguish AMD patients from healthy controls (area under the receiver operator curve $=0.74$ ) and suggested that similar scores could be used to identify and prioritize at-risk individuals, in order to provide them preventive treatment before the disease onset. The development of an efficient tool able to predict the development of AMD is strongly awaited, as it could have a remarkable impact on the health systems. However, several biases can counteract the expectation to achieve reliable data on this complex topic. Many small clinicogenetic studies and, despite adequate statistical protection from multiple comparisons, some GWASs are at risk of findings by chance or of overestimating marker effects [184, 185]. Therefore, correct translational information from genomic marker research to clinical practice of AMD will be more rapidly available if biomedical community works together in carrying out large-scale consortium of trials designed to concomitantly verify the weight of both clinical [13] and genotypic [24] risk factors in AMD patients, as recently performed by Seddon and co-workers in a quite numerous sample population [186]. Before long, the validation of risk prediction models, inclusive of proteomic biomarkers, will be useful for the managing of research, clinical trials, and personalized medicine not only in AMD, but also in other frequent causes of legal blindness such as diabetic retinopathy, glaucoma, and pathologic myopia [1]. In particular, AMD risk scores based only on simple sums of genotypes are unlikely to turn out effective, probably because the complex nature of AMD etiology includes synergistic interactions both among gene variants and among these and environmental conditions. A more comprehensive exploratory approach on the relationship between the chief AMD-risk genotypes, the underlying immunoinflammatory endophenotypes, and the networks of interaction with acquired or epigenetic factors is likely to provide, in the near future, the knowledge for the development of useful predictive algorithms, able to guide in the direction of an effective primary and secondary prevention of AMD.

\section{Conflict of Interests}

The authors declare that there is no conflict of interests regarding the publication of this paper.

\section{References}

[1] S. Resnikoff, D. Pascolini, D. Etya'ale et al., "Global data on visual impairment in the year 2002," Bulletin of the World Health Organization, vol. 82, no. 11, pp. 844-851, 2004.

[2] R. Klein, C.-F. Chou, B. E. K. Klein, X. Zhang, S. M. Meuer, and J. B. Saaddine, "Prevalence of age-related macular degeneration in the US population," Archives of Ophthalmology, vol. 129, no. 1, pp. 75-80, 2011.

[3] W. R. Green and C. Enger, "Age-related macular degeneration histopathologic studies: the 1992 Lorenz E. Zimmerman lecture," Ophthalmology, vol. 100, no. 10, pp. 1519-1535, 1993.

[4] W. R. Green, "Histopathology of age-related macular degeneration," Molecular vision, vol. 5, p. 27, 1999.

[5] G. S. Hageman, P. J. Luthert, N. H. Victor Chong, L. V. Johnson, D. H. Anderson, and R. F. Mullins, "An integrated hypothesis that considers drusen as biomarkers of immunemediated processes at the RPE-Bruch's membrane interface in 
aging and age-related macular degeneration," Progress in Retinal and Eye Research, vol. 20, no. 6, pp. 705-732, 2001.

[6] K. M. Gehrs, D. H. Anderson, L. V. Johnson, and G. S. Hageman, "Age-related macular degeneration-emerging pathogenetic and therapeutic concepts," Annals of Medicine, vol. 38, no. 7, pp. 450-471, 2006.

[7] S. Sarks, S. Cherepanoff, M. Killingsworth, and J. Sarks, "Relationship of basal laminar deposit and membranous debris to the clinical presentation of early age-related macular degeneration," Investigative Ophthalmology and Visual Science, vol. 48, no. 3, pp. 968-977, 2007.

[8] F. Parmeggiani, M. R. Romano, C. Costagliola et al., "Mechanism of inflammation in age-related macular degeneration," Mediators of Inflammation, vol. 2012, Article ID 546786, 16 pages, 2012.

[9] S. Y. Kim, S. Sadda, J. Pearlman et al., "Morphometric analysis of the macula in eyes with disciform age-related macular degeneration," Retina, vol. 22, no. 4, pp. 471-477, 2002.

[10] H. E. Grossniklaus and W. R. Green, "Choroidal neovascularization," American Journal of Ophthalmology, vol. 137, no. 3, pp. 496-503, 2004.

[11] C. Campa, C. Costagliola, C. Incorvaia et al., "Inflammatory mediators and angiogenic factors in choroidal neovascularization: pathogenetic interactions and therapeutic implications," Mediators of Inflammation, vol. 2010, Article ID 546826, 14 pages, 2010.

[12] H. R. Coleman, C.-C. Chan, F. L. Ferris III, and E. Y. Chew, "Agerelated macular degeneration," The Lancet, vol. 372, no. 9652, pp. 1835-1845, 2008.

[13] U. Chakravarthy, T. Y. Wong, A. Fletcher et al., "Clinical risk factors for age-related macular degeneration: a systematic review and meta-analysis," BMC Ophthalmology, vol. 10, no. 1, article 31, 2010.

[14] H. Shahid, J. C. Khan, V. Cipriani et al., "Age-related macular degeneration: the importance of family history as a risk factor," British Journal of Ophthalmology, vol. 96, no. 3, pp. 427-431, 2012.

[15] C. C. Klaver, R. C. Wolfs, J. J. Assink, C. M. van Duijn, A. Hofman, and P. T. de Jong, "Genetic risk of age-related maculopathy: population-based familial aggregation study," Archives of Ophthalmology, vol. 116, no. 12, pp. 1646-1651, 1998.

[16] B. E. Klein, R. Klein, K. E. Lee, E. L. Moore, and L. Danforth, "Risk of incident age-related eye diseases in people with an affected sibling: the Beaver Dam eye study," American Journal of Epidemiology, vol. 154, no. 3, pp. 207-211, 2001.

[17] L. G. Hyman, A. M. Lilienfeld, F. L. Ferris III, and S. L. Fine, "Senile macular degeneration: a case-control study" American Journal of Epidemiology, vol. 118, no. 2, pp. 213-227, 1983.

[18] G. Silvestri, P. B. Johnston, and A. E. Hughes, "Is genetic predisposition an important risk factor in age-related macular degeneration?” Eye, vol. 8, no. 5, pp. 564-568, 1994.

[19] J. M. Seddon, U. A. Ajani, and B. D. Mitchell, "Familial aggregation of age-related maculopathy," American Journal of Ophthalmology, vol. 123, no. 2, pp. 199-206, 1997.

[20] W. Smith and P. Mitchell, "Family history and age-related maculopathy: the Blue Mountains Eye Study," Australian and New Zealand Journal of Ophthalmology, vol. 26, no. 3, pp. 203206, 1998.

[21] L. M. Hjelmeland, "Dark matters in AMD genetics: epigenetics and stochasticity," Investigative Ophthalmology and Visual Science, vol. 52, no. 3, pp. 1622-1631, 2011.
[22] M. M. Liu, C. C. Chan, and J. Tuo, "Genetic mechanisms and age-related macular degeneration: common variants, rare variants, copy number variations, epigenetics, and mitochondrial genetics," Human Genomics, vol. 6, article 13, 2012.

[23] S. He, X. Li, N. Chan, and D. R. Hinton, "Review: epigenetic mechanisms in ocular disease," Molecular Vision, vol. 19, pp. 665-674, 2013.

[24] L. G. Fritsche, W. Chen, M. Schu et al., "Seven new loci associated with age-related macular degeneration," Nature Genetics, vol. 45, no. 4, pp. 433-439, 2013.

[25] Y. Yu, T. R. Bhangale, J. Fagerness et al., “Common variants near FRK/COL10A1 and VEGFA are associated with advanced agerelated macular degeneration," Human Molecular Genetics, vol. 20, no. 18, pp. 3699-3709, 2011.

[26] P. J. Francis and M. L. Klein, "Update on the role of genetics in the onset of age-related macular degeneration," Clinical Ophthalmology, vol. 5, no. 1, pp. 1127-1133, 2011.

[27] A. Thakkinstian, M. McEvoy, U. Chakravarthy et al., "The association between complement component 2/complement factor B polymorphisms and age-related macular degeneration: a HuGE review and meta-analysis," American Journal of Epidemiology, vol. 176, no. 5, pp. 361-372, 2012.

[28] S. Ennis, C. Jomary, R. Mullins et al., "Association between the SERPING1 gene and age-related macular degeneration: a twostage case-control study," The Lancet, vol. 372, no. 9652, pp. 1828-1834, 2008.

[29] J. A. Fagerness, J. B. Maller, B. M. Neale, R. C. Reynolds, M. J. Daly, and J. M. Seddon, "Variation near complement factor I is associated with risk of advanced AMD," European Journal of Human Genetics, vol. 17, no. 1, pp. 100-104, 2009.

[30] Y. Tong, J. Liao, Y. Zhang, J. Zhou, H. Zhang, and M. Mao, "LOC387715/HTRA1 gene polymorphisms and susceptibility to agerelated macular degeneration: a HuGE review and metaanalysis," Molecular Vision, vol. 16, pp. 1958-1981, 2010.

[31] W. Chen, D. Stambolian, A. O. Edwards et al., "Genetic variants near TIMP3 and high-density lipoprotein-associated loci influence susceptibility to age-related macular degeneration," Proceedings of the National Academy of Sciences of the United States of America, vol. 107, no. 16, pp. 7401-7406, 2010.

[32] B. M. Neale, J. Fagerness, R. Reynolds et al., "Genome-wide association study of advanced age-related macular degeneration identifies a role of the hepatic lipase gene (LIPC)," Proceedings of the National Academy of Sciences of the United States of America, vol. 107, no. 16, pp. 7395-7400, 2010.

[33] A. Galan, A. Ferlin, L. Caretti et al., "Association of agerelated macular degeneration with polymorphisms in vascular endothelial growth factor and its receptor," Ophthalmology, vol. 117, no. 9, pp. 1769-1774, 2010.

[34] G. S. Hageman, K. Gehrs, S. Lejnine et al., "Clinical validation of a genetic model to estimate the risk of developing choroidal neovascular age-related macular degeneration," Human Genomics, vol. 5, no. 5, pp. 420-440, 2011.

[35] J. Sawitzke, K. M. Im, B. Kostiha, M. Dean, and B. Gold, "Association assessment of copy number polymorphism and risk of age-related macular degeneration," Ophthalmology, vol. 118, no. 12, pp. 2442-2446, 2011.

[36] A. Thakkinstian, G. J. McKay, M. McEvoy et al., "Systematic review and meta-analysis of the association between complement component 3 and age-related macular degeneration: a HuGE review and meta-analysis," American Journal of Epidemiology, vol. 173, no. 12, pp. 1365-1379, 2011. 
[37] R. Sofat, J. P. Casas, A. R. Webster et al., "Complement factor $\mathrm{H}$ genetic variant and age-related macular degeneration: effect size, modifiers and relationship to disease subtype," International Journal of Epidemiology, vol. 41, no. 1, pp. 250-262, 2012.

[38] M. J. Walport, "Advances in immunology: complement (first of two parts)," The New England Journal of Medicine, vol. 344, no. 14, pp. 1058-1066, 2001.

[39] M. J. Walport, "Advances in immunology: complement (second of two parts)," The New England Journal of Medicine, vol. 344, no. 15, pp. 1140-1144, 2001.

[40] D. Ricklin and J. D. Lambris, "Complement in immune and inflammatory disorders: pathophysiological mechanisms," The Journal of Immunology, vol. 190, no. 8, pp. 3831-3838, 2013.

[41] J. P. Atkinson and M. M. Frank, "Bypassing complement: evolutionary lessons and future implications," Journal of Clinical Investigation, vol. 116, no. 5, pp. 1215-1218, 2006.

[42] M. M. Markiewski, B. Nilsson, K. Nilsson Ekdahl, T. E. Mollnes, and J. D. Lambris, "Complement and coagulation: strangers or partners in crime?" Trends in Immunology, vol. 28, no. 4, pp. 184-192, 2007.

[43] D. Spitzer, L. M. Mitchell, J. P. Atkinson, and D. E. Hourcade, "Properdin can initiate complement activation by binding specific target surfaces and providing a platform for de novo convertase assembly," The Journal of Immunology, vol. 179, no. 4, pp. 2600-2608, 2007.

[44] D. Ricklin and J. D. Lambris, "Complement-targeted therapeutics," Nature Biotechnology, vol. 25, no. 11, pp. 1265-1275, 2007.

[45] K. Yang, R. A. de Angelis, J. E. Reed, D. Ricklin, and J. D. Lambris, "Complement in action: an analysis of patent trends from 1976 through 2011," Advances in Experimental Medicine and Biology, vol. 734, pp. 301-313, 2013.

[46] J. D. Lambris, D. Ricklin, and B. V. Geisbrecht, "Complement evasion by human pathogens," Nature Reviews Microbiology, vol. 6, no. 2, pp. 132-142, 2008.

[47] X. Ding, M. Patel, and C.-C. Chan, "Molecular pathology of age-related macular degeneration," Progress in Retinal and Eye Research, vol. 28, no. 1, pp. 1-18, 2009.

[48] H. Xu, M. Chen, and J. V. Forrester, "Para-inflammation in the aging retina," Progress in Retinal and Eye Research, vol. 28, no. 5, pp. 348-368, 2009.

[49] M. Chen, J. V. Forrester, and H. Xu, "Dysregulation in retinal para-inflammation and age-related retinal degeneration in CCL2 or CCR2 deficient mice," PLoS One, vol. 6, no. 8, Article ID e22818, 2011.

[50] D. H. Anderson, M. J. Radeke, N. B. Gallo et al., “The pivotal role of the complement system in aging and age-related macular degeneration: hypothesis re-visited," Progress in Retinal and Eye Research, vol. 29, no. 2, pp. 95-112, 2010.

[51] L. A. Donoso, T. Vrabec, and H. Kuivaniemi, "The role of complement factor $\mathrm{H}$ in age-related macular degeneration: a review," Survey of Ophthalmology, vol. 55, no. 3, pp. 227-246, 2010.

[52] L. V. Johnson, D. L. Forest, C. D. Banna et al., "Cell culture model that mimics drusen formation and triggers complement activation associated with age-related macular degeneration," Proceedings of the National Academy of Sciences of the United States of America, vol. 108, no. 45, pp. 18277-18282, 2011.

[53] S. Khandhadia, V. Cipriani, J. R. W. Yates, and A. J. Lotery, "Agerelated macular degeneration and the complement system," Immunobiology, vol. 217, no. 2, pp. 127-146, 2012.
[54] J. Tuo, B. C. Smith, C. M. Bojanowski et al., "The involvement of sequence variation and expression of CX3CR1 in the pathogenesis of age-related macular degeneration," FASEB Journal, vol. 18, no. 11, pp. 1297-1299, 2004.

[55] P. J. Francis, S. C. Hamon, J. Ott, R. G. Weleber, and M. L. Klein, "Polymorphisms in C2, CFB and C3 are associated with progression to advanced age related macular degeneration associated with visual loss," Journal of Medical Genetics, vol. 46, no. 5, pp. 300-307, 2009.

[56] F. Ricci, S. Zampatti, F. D’Abbruzzi et al., “Typing of ARMS2 and $\mathrm{CFH}$ in age-related macular degeneration: case-control study and assessment of frequency in the Italian population," Archives of Ophthalmology, vol. 127, no. 10, pp. 1368-1372, 2009.

[57] E. Ryu, B. L. Fridley, N. Tosakulwong, K. R. Bailey, and A. O. Edwards, "Genome-wide association analyses of genetic, phenotypic, and environmental risks in the age-related eye disease study," Molecular Vision, vol. 16, pp. 2811-2821, 2010.

[58] I. Peter and J. M. Seddon, "Genetic epidemiology: successes and challenges of genome-wide association studies using the example of age-related macular degeneration," American Journal of Ophthalmology, vol. 150, no. 4, pp. 450-452, 2010.

[59] K. J. Meyer, L. K. Davis, E. I. Schindler et al., "Genomewide analysis of copy number variants in age-related macular degeneration," Human Genetics, vol. 129, no. 1, pp. 91-100, 2011.

[60] P. L. Penfold, M. C. Killingsworth, and S. H. Sarks, "Senile macular degeneration: the involvement of immunocompetent cells," Graefe's Archive for Clinical and Experimental Ophthalmology, vol. 223, no. 2, pp. 69-76, 1985.

[61] P. F. Lopez, H. E. Grossniklaus, H. M. Lambert et al., "Pathologic features of surgically excised subretinal neovascular membranes in age-related macular degeneration," American Journal of Ophthalmology, vol. 112, no. 6, pp. 647-656, 1991.

[62] R. F. Mullins, S. R. Russell, D. H. Anderson, and G. S. Hageman, "Drusen associated with aging and age-related macular degeneration contain proteins common to extracellular deposits associated with atherosclerosis, elastosis, amyloidosis, and dense deposit disease," FASEB Journal, vol. 14, no. 7, pp. 835$846,2000$.

[63] L. V. Johnson, S. Ozaki, M. K. Staples, P. A. Erickson, and D. H. Anderson, "A potential role for immune complex pathogenesis in drusen formation," Experimental Eye Research, vol. 70, no. 4, pp. 441-449, 2000.

[64] J. L. Haines, M. A. Hauser, S. Schmidt et al., "Complement factor $\mathrm{H}$ variant increases the risk of age-related macular degeneration," Science, vol. 308, no. 5720, pp. 419-421, 2005.

[65] M. Nozaki, B. J. Raisler, E. Sakurai et al., "Drusen complement components C3a and C5a promote choroidal neovascularization," Proceedings of the National Academy of Sciences of the United States of America, vol. 103, no. 7, pp. 2328-2333, 2006.

[66] A. Lommatzsch, P. Hermans, B. Weber, and D. Pauleikhoff, "Complement factor $\mathrm{H}$ variant $\mathrm{Y} 402 \mathrm{H}$ and basal laminar deposits in exudative age-related macular degeneration," Graefe's Archive for Clinical and Experimental Ophthalmology, vol. 245, no. 11, pp. 1713-1716, 2007.

[67] A. Lommatzsch, P. Hermans, K. D. Müller, N. Bornfeld, A. C. Bird, and D. Pauleikhoff, "Are low inflammatory reactions involved in exudative age-related macular degeneration?" Graefe's Archive for Clinical and Experimental Ophthalmology, vol. 246, no. 6, pp. 803-810, 2008.

[68] I. A. Bhutto, T. Baba, C. Merges, V. Juriasinghani, D. S. McLeod, and G. A. Lutty, "C-reactive protein and complement factor 
$\mathrm{H}$ in aged human eyes and eyes with age-related macular degeneration," British Journal of Ophthalmology, vol. 95, no. 9, pp. 1323-1330, 2011.

[69] A. L. Fett, M. M. Hermann, P. S. Muether, B. Kirchhof, and S. Fauser, "Immunohistochemical localization of complement regulatory proteins in the human retina," Histology and Histopathology, vol. 27, no. 3, pp. 357-364, 2012.

[70] S. Sivaprasad, T. Adewoyin, T. A. Bailey et al., "Estimation of systemic complement $\mathrm{C} 3$ activity in age-related macular degeneration," Archives of Ophthalmology, vol. 125, no. 4, pp. 515-519, 2007.

[71] H. P. Scholl, I. P. Charbel, M. Walier et al., "Systemic complement activation in age-related macular degeneration," PLoS One, vol. 3, no. 7, Article ID e2593, 2008.

[72] A. MacHalińska, V. Dziedziejko, K. Mozolewska-Piotrowska, D. Karczewicz, B. Wiszniewska, and B. MacHaliński, "Elevated plasma levels of c3a complement compound in the exudative form of age-related macular degeneration," Ophthalmic Research, vol. 42, no. 1, pp. 54-59, 2009.

[73] A. Richards, D. Kavanagh, and J. P. Atkinson, "Inherited complement regulatory protein deficiency predisposes to human disease in acute injury and chronic inflammatory statesthe examples of vascular damage in atypical hemolytic uremic syndrome and debris accumulation in age-related macular degeneration," Advances in Immunology, vol. 96, pp. 141-177, 2007.

[74] T. H. J. Goodship, "Factor H genotype-phenotype correlations: lessons from aHUS, MPGN II, and AMD," Kidney International, vol. 70, no. 1, pp. 12-13, 2006.

[75] P. F. Zipfel, N. Lauer, and C. Skerka, "The role of complement in AMD," Advances in Experimental Medicine and Biology, vol. 703, pp. 9-24, 2010.

[76] J. Tuo, S. Grob, K. Zhang, and C.-C. Chan, "Genetics of immunological and inflammatory components in age-related macular degeneration," Ocular Immunology and Inflammation, vol. 20, no. 1, pp. 27-36, 2012.

[77] J. R. Sparrow, K. Ueda, and J. Zhou, "Complement dysregulation in AMD: RPE-Bruch's membrane-choroid," Molecular Aspects of Medicine, vol. 33, no. 4, pp. 436-445, 2012.

[78] A. Wenzel, C. Grimm, M. Samardzija, and C. E. Remé, "Molecular mechanisms of light-induced photoreceptor apoptosis and neuroprotection for retinal degeneration," Progress in Retinal and Eye Research, vol. 24, no. 2, pp. 275-306, 2005.

[79] J. Wu, S. Seregard, and P. V. Algvere, "Photochemical damage of the retina," Survey of Ophthalmology, vol. 51, no. 5, pp. 461-481, 2006.

[80] M. Cano, R. Thimmalappula, M. Fujihara et al., "Cigarette smoking, oxidative stress, the anti-oxidant response through Nrf2 signaling, and Age-related Macular Degeneration," Vision Research, vol. 50, no. 7, pp. 652-664, 2010.

[81] A. U. Kishan, B. S. Modjtahedi, E. N. Martins, S. P. Modjtahedi, and L. S. Morse, "Lipids and age-related macular degeneration," Survey of Ophthalmology, vol. 56, no. 3, pp. 195-213, 2011.

[82] E. Naik and V. M. Dixit, "Mitochondrial reactive oxygen species drive proinflammatory cytokine production," Journal of Experimental Medicine, vol. 208, no. 3, pp. 417-420, 2011.

[83] H. Kajimoto, K. Hashimoto, S. N. Bonnet et al., "Oxygen activates the rho/rho-kinase pathway and induces RhoB and ROCK-1 expression in human and rabbit ductus arteriosus by increasing mitochondria-derived reactive oxygen species: a newly recognized mechanism for sustaining ductal constriction," Circulation, vol. 115, no. 13, pp. 1777-1788, 2007.
[84] J. Zhou, Y. P. Jang, S. R. Kim, and J. R. Sparrow, “Complement activation by photooxidation products of A2E, a lipofuscin constituent of the retinal pigment epithelium," Proceedings of the National Academy of Sciences of the United States of America, vol. 103, no. 44, pp. 16182-16187, 2006.

[85] J. Zhou, S. R. Kim, B. S. Westlund, and J. R. Sparrow, "Complement activation by bisretinoid constituents of RPE lipofuscin," Investigative Ophthalmology and Visual Science, vol. 50, no. 3, pp. 1392-1399, 2009.

[86] J. L. Dunaief, T. Dentchev, G.-S. Ying, and A. H. Milam, “The role of apoptosis in age-related macular degeneration," Archives of Ophthalmology, vol. 120, no. 11, pp. 1435-1442, 2002.

[87] W. Zheng, R. E. Reem, S. Omarova et al., "Spatial distribution of the pathways of cholesterol homeostasis in human retina," PLOS One, vol. 7, no. 5, Article ID e37926, 2012.

[88] S. J. Fliesler, R. Florman, L. M. Rapp, S. J. Pittler, and R. Kennedy Keller, "In vivo biosynthesis of cholesterol in the rat retina," FEBS Letters, vol. 335, no. 2, pp. 234-238, 1993.

[89] S. J. Fliesler and R. K. Keller, "Isoprenoid metabolism in the vertebrate retina," International Journal of Biochemistry and Cell Biology, vol. 29, no. 6, pp. 877-894, 1997.

[90] N. Tserentsoodol, N. V. Gordiyenko, I. Pascual, J. W. Lee, S. J. Fliesler, and I. R. Rodriguez, "Intraretinal lipid transport is dependent on high density lipoprotein-like particles and class B scavenger receptors," Molecular Vision, vol. 12, pp. 1319-1333, 2006.

[91] C. A. Curcio, M. Johnson, J.-D. Huang, and M. Rudolf, "Aging, age-related macular degeneration, and the response-toretention of apolipoprotein B-containing lipoproteins," Progress in Retinal and Eye Research, vol. 28, no. 6, pp. 393-422, 2009.

[92] C. A. Curcio, M. Johnson, J.-D. Huang, and M. Rudolf, "Apolipoprotein B-containing lipoproteins in retinal aging and age-related macular degeneration," The Journal of Lipid Research, vol. 51, no. 3, pp. 451-467, 2010.

[93] N. Mast, R. Reem, I. Bederman et al., "Cholestenoic acid is an important elimination product of cholesterol in the retina: comparison of retinal cholesterol metabolism with that in the brain," Investigative Ophthalmology and Visual Science, vol. 52, no. 1, pp. 594-603, 2011.

[94] L. Bretillon, U. Diczfalusy, I. Björkhem et al., "Cholesterol-24Shydroxylase (CYP46A1) is specifically expressed in neurons of the neural retina," Current Eye Research, vol. 32, no. 4, pp. 361366, 2007.

[95] W. L. Liao, G. Y. Heo, N. G. Dodder et al., "Quantification of cholesterol-metabolizing p450s CYP27A1 and CYP46A1 in neural tissues reveals a lack of enzyme-product correlations in human retina but not human brain," Journal of Proteome Research, vol. 10, no. 1, pp. 241-248, 2011.

[96] N. Tserentsoodol, J. Sztein, M. Campos et al., "Uptake of cholesterol by the retina occurs primarily via a low density lipoprotein receptor-mediated process," Molecular Vision, vol. 12, pp. 1306-1318, 2006.

[97] V. M. Elner, "Retinal pigment epithelial acid lipase activity and lipoprotein receptors: effects of dietary omega-3 fatty acids," Transactions of the American Ophthalmological Society, vol. 100, pp. 301-338, 2002.

[98] K. Boesze-Battaglia and A. D. Albert, "Cholesterol modulation of photoreceptor function in bovine retinal rod outer segments," The Journal of Biological Chemistry, vol. 265, no. 34, pp. 2072720730, 1990.

[99] T. Claudepierre, M. Paques, M. Simonutti et al., "Lack of Niemann-Pick type $\mathrm{Cl}$ induces age-related degeneration in 
the mouse retina," Molecular and Cellular Neuroscience, vol. 43, no. 1, pp. 164-176, 2010.

[100] S. E. Phillips, E. A. Woodruff III, P. Liang, M. Patten, and K. Broadie, "Neuronal loss of Drosophila NPCla causes cholesterol aggregation and age-progressive neurodegeneration," Journal of Neuroscience, vol. 28, no. 26, pp. 6569-6582, 2008.

[101] P. Borel, "Genetic variations involved in interindividual variability in carotenoid status," Molecular Nutrition and Food Research, vol. 56, no. 2, pp. 228-240, 2012.

[102] D. L. Williams, M. A. Connelly, R. E. Temel et al., "Scavenger receptor BI and cholesterol trafficking," Current Opinion in Lipidology, vol. 10, no. 4, pp. 329-339, 1999.

[103] M. de la Llera-Moya, M. A. Connelly, D. Drazul et al., "Scavenger receptor class B type I affects cholesterol homeostasis by magnifying cholesterol flux between cells and HDL," The Journal of Lipid Research, vol. 42, no. 12, pp. 1969-1978, 2001.

[104] F. W. Pfrieger, "Cholesterol homeostasis and function in neurons of the central nervous system," Cellular and Molecular Life Sciences, vol. 60, no. 6, pp. 1158-1171, 2003.

[105] C. Cavelier, I. Lorenzi, L. Rohrer, and A. von Eckardstein, "Lipid efflux by the ATP-binding cassette transporters ABCA1 and ABCG1," Biochimica et Biophysica Acta, vol. 1761, no. 7, pp. 655666, 2006.

[106] A. Sene, A. A. Khan, D. Cox et al., "Impaired cholesterol efflux in senescent macrophages promotes age-related macular degeneration," Cell Metabolism, vol. 17, no. 4, pp. 549-561, 2013.

[107] G. J. McKay, E. Loane, J. M. Nolan et al., "Investigation of genetic variation in scavenger receptor class b, member 1 (SCARB1) and association with serum carotenoids," Ophthalmology, vol. 120, no. 8, pp. 1632-1640, 2013.

[108] A. D. Albert and K. Boesze-Battaglia, "The role of cholesterol in rod outer segment membranes," Progress in Lipid Research, vol. 44, no. 2-3, pp. 99-124, 2005.

[109] J. Chen and L. E. Smith, "Altered cholesterol homeostasis in aged macrophages linked to neovascular macular degeneration," Cell Metabolism, vol. 17, no. 4, pp. 471-472, 2013.

[110] N. Gordiyenko, M. Campos, J. W. Lee, R. N. Fariss, J. Sztein, and I. R. Rodriguez, "RPE cells internalize low-density lipoprotein (LDL) and oxidized LDL (oxLDL) in large quantities in vitro and in vivo," Investigative Ophthalmology and Visual Science, vol. 45, no. 8, pp. 2822-2829, 2004.

[111] N. Tserentsoodol, J. Sztein, M. Campos et al., "Uptake of cholesterol by the retina occurs primarily via a low density lipoprotein receptor-mediated process," Molecular Vision, vol. 12, pp. 1306-1318, 2006.

[112] K. J. Williams and I. Tabas, "The response-to-retention hypothesis of early atherogenesis," Arteriosclerosis, Thrombosis, and Vascular Biology, vol. 15, no. 5, pp. 551-562, 1995.

[113] C. K. Glass and J. L. Witztum, "Atherosclerosis: the road ahead," Cell, vol. 104, no. 4, pp. 503-516, 2001.

[114] J. L. Goldstein and M. S. Brown, "The cholesterol quartet," Science, vol. 292, no. 5520, pp. 1310-1312, 2001.

[115] R. K. Tangirala, E. D. Bischoff, S. B. Joseph et al., "Identification of macrophage liver X receptors as inhibitors of atherosclerosis," Proceedings of the National Academy of Sciences of the United States of America, vol. 99, no. 18, pp. 11896-11901, 2002.

[116] E. D. Bischoff, C. L. Daige, M. Petrowski et al., "Non-redundant roles for LXR $\alpha$ and $\operatorname{LXR} \beta$ in atherosclerosis susceptibility in low density lipoprotein receptor knockout mice," The Journal of Lipid Research, vol. 51, no. 5, pp. 900-906, 2010.
[117] R. Feldmann, C. Fischer, V. Kodelja et al., "Genome-wide analysis of LXR $\alpha$ activation reveals new transcriptional networks in human atherosclerotic foam cells," Nucleic Acids Research, vol. 41, no. 6, pp. 3518-3531, 2013.

[118] I. Tabas, K. J. Williams, and J. Borén, "Subendothelial lipoprotein retention as the initiating process in atherosclerosis: update and therapeutic implications," Circulation, vol. 116, no. 16, pp. 1832-1844, 2007.

[119] K. J. Moore and I. Tabas, "Macrophages in the pathogenesis of atherosclerosis," Cell, vol. 145, no. 3, pp. 341-355, 2011.

[120] D. Pauleikhoff, C. A. Harper, J. Marshall, and A. C. Bird, "Aging changes in Bruch's membrane. A histochemical and morphologic study," Ophthalmology, vol. 97, no. 2, pp. 171-178, 1990.

[121] F. G. Holz, G. Sheraidah, D. Pauleikhoff, and A. C. Bird, "Analysis of lipid deposits extracted from human macular and peripheral Bruch's membrane," Archives of Ophthalmology, vol. 112, no. 3, pp. 402-406, 1994.

[122] C. A. Curcio, M. Johnson, M. Rudolf, and J.-D. Huang, "The oil spill in ageing Bruch membrane," British Journal of Ophthalmology, vol. 95, no. 12, pp. 1638-1645, 2011.

[123] I. R. Rodríguez and I. M. Larrayoz, "Cholesterol oxidation in the retina: implications of $7 \mathrm{KCh}$ formation in chronic inflammation and age-related macular degeneration," The Journal of Lipid Research, vol. 51, no. 10, pp. 2847-2862, 2010.

[124] S. Lordan, J. J. Mackrill, and N. M. O’Brien, “Oxysterols and mechanisms of apoptotic signaling: implications in the pathology of degenerative diseases," The Journal of Nutritional Biochemistry, vol. 20, no. 5, pp. 321-336, 2009.

[125] G. Poli, B. Sottero, S. Gargiulo, and G. Leonarduzzi, "Cholesterol oxidation products in the vascular remodeling due to atherosclerosis," Molecular Aspects of Medicine, vol. 30, no. 3, pp. 180-189, 2009.

[126] A. Vejux and G. Lizard, "Cytotoxic effects of oxysterols associated with human diseases: induction of cell death (apoptosis and/or oncosis), oxidative and inflammatory activities, and phospholipidosis," Molecular Aspects of Medicine, vol. 30, no. 3, pp. 153-170, 2009.

[127] D. Töröcsik, A. Szanto, and L. Nagy, "Oxysterol signaling links cholesterol metabolism and inflammation via the liver X receptor in macrophages," Molecular Aspects of Medicine, vol. 30, no. 3, pp. 134-152, 2009.

[128] H. Hakamata, A. Miyazaki, M. Sakai, Y. I. Sakamoto, and S. Horiuchi, "Cytotoxic effect of oxidized low density lipoprotein on macrophages," Journal of Atherosclerosis and Thrombosis, vol. 5, no. 2, pp. 66-75, 1998.

[129] T. Seimon and I. Tabas, "Mechanisms and consequences of macrophage apoptosis in atherosclerosis," The Journal of Lipid Research, vol. 50, pp. S382-S387, 2009.

[130] I. Tabas, "Macrophage death and defective inflammation resolution in atherosclerosis," Nature Reviews Immunology, vol. 10, no. 1, pp. 36-46, 2010.

[131] I. Björkhem, A. Cedazo-Minguez, V. Leoni, and S. Meaney, "Oxysterols and neurodegenerative diseases," Molecular Aspects of Medicine, vol. 30, no. 3, pp. 171-179, 2009.

[132] V. M. Olkkonen and R. Hynynen, "Interactions of oxysterols with membranes and proteins," Molecular Aspects of Medicine, vol. 30, no. 3, pp. 123-133, 2009.

[133] A. J. Brown and W. Jessup, "Oxysterols: sources, cellular storage and metabolism, and new insights into their roles in cholesterol homeostasis," Molecular Aspects of Medicine, vol. 30, no. 3, pp. 111-122, 2009. 
[134] E. F. Moreira, I. M. Larrayoz, J. W. Lee, and I. R. Rodríguez, "7-Ketocholesterol is present in lipid deposits in the primate retina: potential implication in the induction of VEGF and CNV formation," Investigative Ophthalmology and Visual Science, vol. 50, no. 2, pp. 523-532, 2009.

[135] S. Dzeletovic, A. Babiker, E. Lund, and U. Diczfalusy, "Time course of oxysterol formation during in vitro oxidation of low density lipoprotein," Chemistry and Physics of Lipids, vol. 78, no. 2, pp. 119-128, 1995.

[136] A. W. Girotti, "Photosensitized oxidation of cholesterol in biological systems: reaction pathways, cytotoxic effects and defense mechanisms," Journal of Photochemistry and Photobiology B, vol. 13, no. 2, pp. 105-118, 1992.

[137] N. Stadler, R. A. Lindner, and M. J. Davies, "Direct detection and quantification of transition metal ions in human atherosclerotic plaques: evidence for the presence of elevated levels of iron and copper," Arteriosclerosis, Thrombosis, and Vascular Biology, vol. 24, no. 5, pp. 949-954, 2004.

[138] A. W. Girotti and W. Korytowski, "Cholesterol as a singlet oxygen detector in biological systems," Methods in Enzymology, vol. 319, pp. 85-100, 2000.

[139] W. Korytowski, G. J. Bachowski, and A. W. Girotti, "Photoperoxidation of cholesterol in homogeneous solution, isolated membranes, and cells: comparison of the 5 alpha- and 6 betahydroperoxides as indicators of singlet oxygen intermediacy," Photochemistry and Photobiology, vol. 56, no. 1, pp. 1-8, 1992.

[140] A. Lakkaraju, S. C. Finnemann, and E. Rodriguez-Boulan, "The lipofuscin fluorophore A2E perturbs cholesterol metabolism in retinal pigment epithelial cells," Proceedings of the National Academy of Sciences of the United States of America, vol. 104, no. 26, pp. 11026-11031, 2007.

[141] A. O. Edwards, R. Ritter III, K. J. Abel, A. Manning, C. Panhuysen, and L. A. Farrer, "Complement factor H polymorphism and age-related macular degeneration," Science, vol. 308, no. 5720, pp. 421-424, 2005.

[142] R. J. Klein, C. Zeiss, E. Y. Chew et al., "Complement factor H polymorphism in age-related macular degeneration," Science, vol. 308, no. 5720, pp. 385-389, 2005.

[143] G. S. Hageman, D. H. Anderson, L. V. Johnson et al., "A common haplotype in the complement regulatory gene factor $\mathrm{H}$ ( $\mathrm{HF} 1 / \mathrm{CFH})$ predisposes individuals to age-related macular degeneration," Proceedings of the National Academy of Sciences of the United States of America, vol. 102, no. 20, pp. 7227-7232, 2005.

[144] J. Maller, S. George, S. Purcell et al., "Common variation in three genes, including a noncoding variant in $\mathrm{CFH}$, strongly influences risk of age-related macular degeneration," Nature Genetics, vol. 38, no. 9, pp. 1055-1059, 2006.

[145] B. Gold, J. E. Merriam, J. Zernant et al., "Variation in factor B (BF) and complement component 2 (C2) genes is associated with age-related macular degeneration," Nature Genetics, vol. 38, no. 4, pp. 458-462, 2006.

[146] J. B. Maller, J. A. Fagerness, R. C. Reynolds, B. M. Neale, M. J. Daly, and J. M. Seddon, "Variation in complement factor 3 is associated with risk of age-related macular degeneration," Nature Genetics, vol. 39, no. 10, pp. 1200-1201, 2007.

[147] J. R. Yates, T. Sepp, B. K. Matharu et al., "Complement C3 variant and the risk of age-related macular degeneration," The New England Journal of Medicine, vol. 357, no. 6, pp. 553-561, 2007.
[148] C. E. Gallenga, F. Parmeggiani, C. Costagliola, A. Sebastiani, and P. E. Gallenga, "Inflammaging: should this term be suitable for age related macular degeneration too?" Inflammation Research, 2013.

[149] T. Takabayashi, E. Vannier, J. F. Burke, R. G. Tompkins, J. A. Gelfand, and B. D. Clark, "Both C3a and C3a(desArg) regulate interleukin-6 synthesis in human peripheral blood mononuclear cells," Journal of Infectious Diseases, vol. 177, no. 6, pp. 1622-1628, 1998.

[150] B. H. Ault, "Factor H and the pathogenesis of renal diseases," Pediatric Nephrology, vol. 14, no. 10-11, pp. 1045-1053, 2000.

[151] D. Pérez-Caballero, C. González-Rubio, M. Esther Gallardo et al., "Clustering of missense mutations in the C-terminal region of factor $\mathrm{H}$ in atypical hemolytic uremic syndrome," American Journal of Human Genetics, vol. 68, no. 2, pp. 478-484, 2001.

[152] E. Giannakis, T. S. Jokiranta, D. A. Male et al., "A common site within factor H SCR 7 responsible for binding heparin, Creactive protein and streptococcal M protein," European Journal of Immunology, vol. 33, no. 4, pp. 962-969, 2003.

[153] C. Mold, M. Kingzette, and H. Gewurz, "C-reactive protein inhibits pneumococcal activation of the alternative pathway by increasing the interaction between factor $\mathrm{H}$ and C3b," The Journal of Immunology, vol. 133, no. 2, pp. 882-885, 1984.

[154] T. Montes, A. Tortajada, B. P. Morgan, S. R. de Córdoba, and C. L. Harris, "Functional basis of protection against age-related macular degeneration conferred by a common polymorphism in complement factor B," Proceedings of the National Academy of Sciences of the United States of America, vol. 106, no. 11, pp. 4366-4371, 2009.

[155] A. P. Sjöberg, L. A. Trouw, S. J. Clark et al., "The factor H variant associated with age-related macular degeneration (His384 ) and the non-disease-associated form bind differentially to C-reactive protein, fibromodulin, DNA, and necrotic cells," The Journal of Biological Chemistry, vol. 282, no. 15, pp. 10894-10900, 2007.

[156] R. J. Ormsby, S. Ranganathan, J. C. Tong et al., "Functional and structural implications of the complement factor $\mathrm{H} \mathrm{Y} 402 \mathrm{H}$ polymorphism associated with Age-Related macular degeneration," Investigative Ophthalmology and Visual Science, vol. 49, no. 5, pp. 1763-1770, 2008.

[157] S. J. Clark, R. Perveen, S. Hakobyan et al., "Impaired binding of the age-related macular degeneration-associated complement factor $\mathrm{H} 402 \mathrm{H}$ allotype to Bruch's membrane in human retina," The Journal of Biological Chemistry, vol. 285, no. 39, pp. 3019230202, 2010.

[158] M. Laine, H. Jarva, S. Seitsonen et al., "Y402H polymorphism of complement factor $\mathrm{H}$ affects binding affinity to $\mathrm{C}$-reactive protein," The Journal of Immunology, vol. 178, no. 6, pp. 38313836, 2007.

[159] V. N. Lauer, M. Mihlan, A. Hartmann et al., "Complement regulation at necrotic cell lesions is impaired by the age-related macular degeneration-associated factor-H His402 risk," The Journal of Immunology, vol. 187, no. 8, pp. 4374-4383, 2011.

[160] S. J. Clark, V. A. Higman, B. Mulloy et al., "His-384 allotypic variant of factor $\mathrm{H}$ associated with age-related macular degeneration has different heparin binding properties from the nondisease-associated form," The Journal of Biological Chemistry, vol. 281, no. 34, pp. 24713-24720, 2006.

[161] J. G. Hollyfield, V. L. Bonilha, M. E. Rayborn et al., “Oxidative damage-induced inflammation initiates age-related macular degeneration," Nature Medicine, vol. 14, no. 2, pp. 194-198, 2008. 
[162] P. T. Johnson, K. E. Betts, M. J. Radeke, G. S. Hageman, D. H. Anderson, and L. V. Johnson, "Individuals homozygous for the age-related macular degeneration risk-conferring variant of complement factor $\mathrm{H}$ have elevated levels of CRP in the choroid," Proceedings of the National Academy of Sciences of the United States of America, vol. 103, no. 46, pp. 17456-17461, 2006.

[163] M. Li, P. Atmaca-Sonmez, M. Othman et al., "CFH haplotypes without the $\mathrm{Y} 402 \mathrm{H}$ coding variant show strong association with susceptibility to age-related macular degeneration," Nature Genetics, vol. 38, no. 9, pp. 1049-1054, 2006.

[164] L. G. Fritsche, T. Loenhardt, A. Janssen et al., "Age-related macular degeneration is associated with an unstable ARMS2 (LOC387715) mRNA," Nature Genetics, vol. 40, no. 7, pp. 892896, 2008.

[165] M.-L. Lokki and S. A. Koskimies, "Allelic differences in hemolytic activity and protein concentration of BF molecules are found in association with particular HLA haplotypes," Immunogenetics, vol. 34, no. 4, pp. 242-246, 1991.

[166] A. E. Hughes, G. M. Mullan, and D. T. Bradley, "Complement factor B polymorphism $32 \mathrm{~W}$ protects against agerelated macular degeneration," Molecular Vision, vol. 17, pp. 983-988, 2011.

[167] H. Kokotas, M. Grigoriadou, and M. B. Petersen, "Age-related macular degeneration: genetic and clinical findings," Clinical Chemistry and Laboratory Medicine, vol. 49, no. 4, pp. 601-616, 2011.

[168] M. Heurich, R. Martínez-Barricarte, N. J. Francis et al., "Common polymorphisms in $\mathrm{C} 3$, factor $\mathrm{B}$, and factor $\mathrm{H}$ collaborate to determine systemic complement activity and disease risk," Proceedings of the National Academy of Sciences of the United States of America, vol. 108, no. 21, pp. 8761-8766, 2011.

[169] D. D. Despriet, C. M. van Duijn, B. A. Oostra et al., "Complement component $\mathrm{C} 3$ and risk of age-related macular degeneration," Ophthalmology, vol. 116, no. 3, pp. 474-480, 2009.

[170] L. Wu, Q. Tao, W. Chen et al., "Association between polymorphisms of complement pathway genes and age-related macular degeneration in a Chinese population," Investigative Ophthalmology \& Visual Science, vol. 54, no. 1, pp. 170-174, 2013.

[171] A. Rivera, S. A. Fisher, L. G. Fritsche et al., "Hypothetical LOC387715 is a second major susceptibility gene for age-related macular degeneration, contributing independently of complement factor H to disease risk," Human Molecular Genetics, vol. 14, no. 21, pp. 3227-3236, 2005.

[172] A. DeWan, M. Liu, S. Hartman et al., "HTRA1 promoter polymorphism in wet age-related macular degeneration," Science, vol. 314, no. 5801, pp. 989-992, 2006.

[173] Z. Yang, N. J. Camp, H. Sun et al., "A variant of the HTRA1 gene increases susceptibility to age-related macular degeneration," Science, vol. 314, no. 5801, pp. 992-993, 2006.

[174] A. Kanda, W. Chen, M. Othman et al., "A variant of mitochondrial protein LOC387715/ARMS2, not HTRA1, is strongly associated with age-related macular degeneration," Proceedings of the National Academy of Sciences of the United States of America, vol. 104, no. 41, pp. 16227-16232, 2007.

[175] G. Wang, S. R. Dubovy, J. L. Kovach et al., "Variants at chromosome 10q26 locus and the expression of HTRA1 in the retina," Experimental Eye Research, vol. 112, pp. 102-105, 2013.

[176] I. Kaur, S. Cantsilieris, S. Katta et al., "Association of the del443ins54 at the ARMS2 locus in Indian and Australian cohorts with age-related macular degeneration," Molecular Vision, vol. 19, pp. 822-828, 2013.

[177] J. H. Qi, Q. Ebrahem, N. Moore et al., "A novel function for tissue inhibitor of metalloproteinases-3 (TIMP3): inhibition of angiogenesis by blockage of VEGF binding to VEGF receptor2," Nature Medicine, vol. 9, no. 4, pp. 407-415, 2003.

[178] M. A. de la Paz, M. A. Pericak-Vance, F. Lennon, J. L. Haines, and J. M. Seddon, "Exclusion of TIMP3 as a candidate locus in age-related macular degeneration," Investigative Ophthalmology and Visual Science, vol. 38, no. 6, pp. 1060-1065, 1997.

[179] U. Felbor, D. Doepner, U. Schneider, E. Zrenner, and B. H. F. Weber, "Evaluation of the gene encoding the tissue inhibitor of metalloproteinases-3 in various maculopathies," Investigative Ophthalmology and Visual Science, vol. 38, no. 6, pp. 1054-1059, 1997.

[180] D. Ardeljan, C. B. Meyerle, E. Agron et al., "Influence of TIMP3/SYN3 polymorphisms on the phenotypic presentation of age-related macular degeneration," European Journal of Human Genetics, vol. 21, no. 10, pp. 1152-1157, 2013.

[181] R. Zeng, F. Wen, X. Zhang et al., "An rs9621532 variant near the TIMP3 gene is not associated with neovascular age-related macular degeneration and polypoidal choroidal vasculopathy in a Chinese Han population," Ophthalmic Genetics, vol. 33, no. 3, pp. 139-143, 2012.

[182] J. Lee, J. Zeng, G. Hughes et al., "Association of LIPC and advanced age-related macular degeneration," Eye, vol. 27, no. 2, pp. 265-270, 2013.

[183] F. Cruz-González, C. Cieza-Borrella, G. López Valverde, R. Lorenzo-Pérez, E. Hernández-Galilea, and R. GonzálezSarmiento, "CFH, (rs1410996), HTRA1 (rs112000638) and ARMS2 (rs10490923) gene polymorphisms are associated with AMD risk in Spanish patients," Ophthalmic Genetics, 2013.

[184] J. P. Ioannidis and O. A. Panagiotou, "Comparison of effect sizes associated with biomarkers reported in highly cited individual articles and in subsequent meta-analyses," Journal of the American Medical Association, vol. 305, no. 21, pp. 2200-2210, 2011.

[185] P. Tajik and P. M. Bossuyt, "Genomic markers to tailor treatments: waiting or initiating?" Human Genetics, vol. 130, no. 1, pp. 15-18, 2011.

[186] J. M. Seddon, R. Reynolds, Y. Yu, and B. Rosner, "Validation of a prediction algorithm for progression to advanced macular degeneration subtypes," JAMA Ophthalmology, vol. 131, no. 4, pp. 448-455, 2013. 


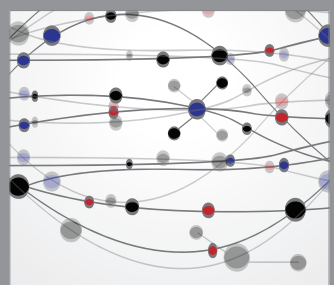

The Scientific World Journal
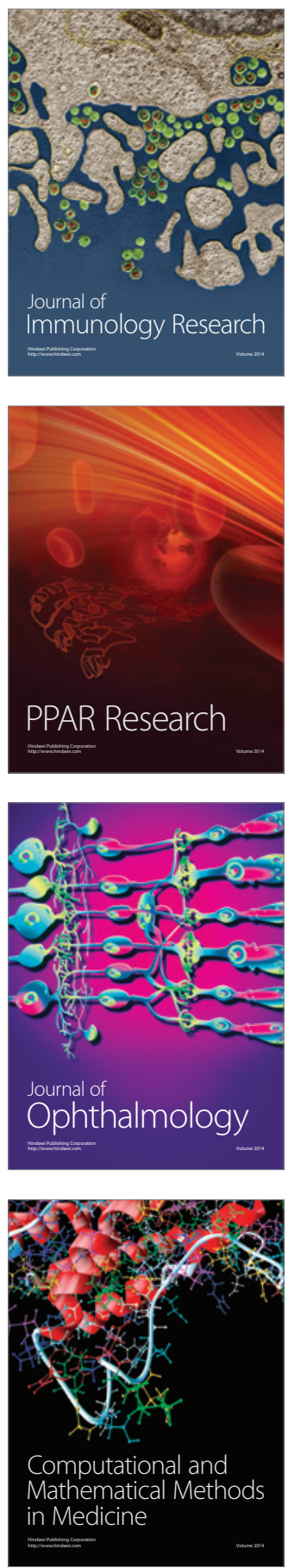

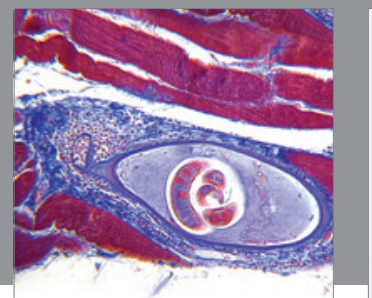

Gastroenterology

Research and Practice
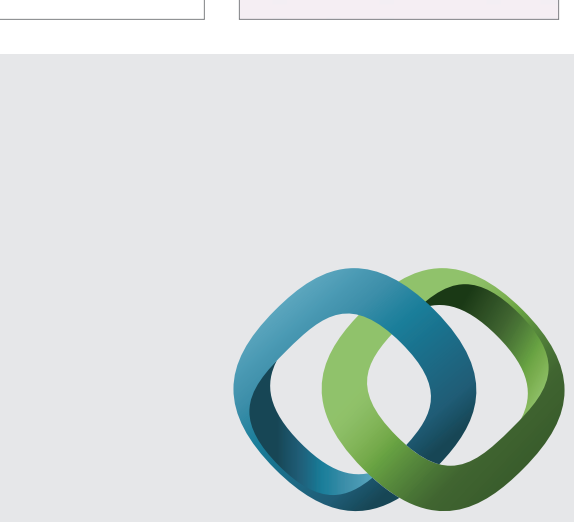

\section{Hindawi}

Submit your manuscripts at

http://www.hindawi.com
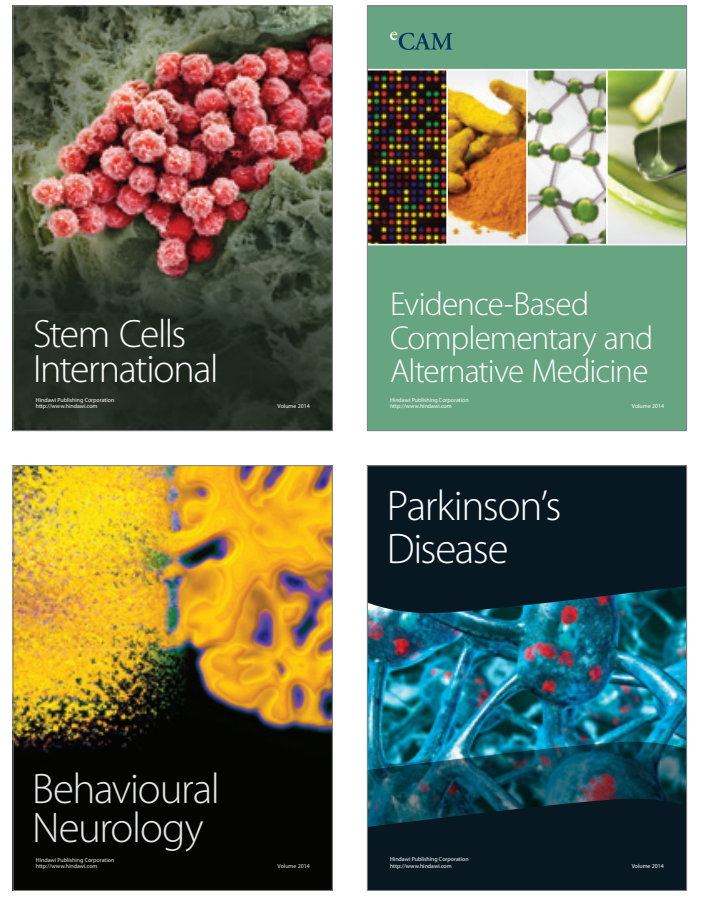
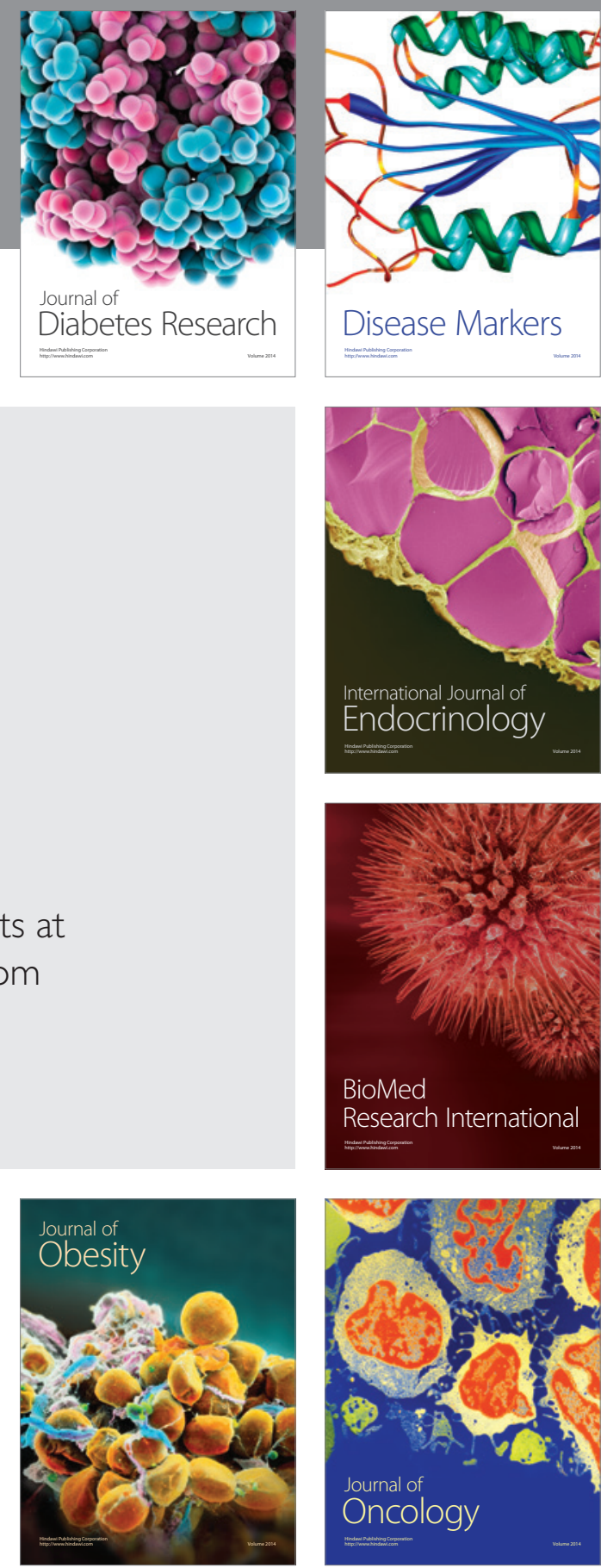

Disease Markers
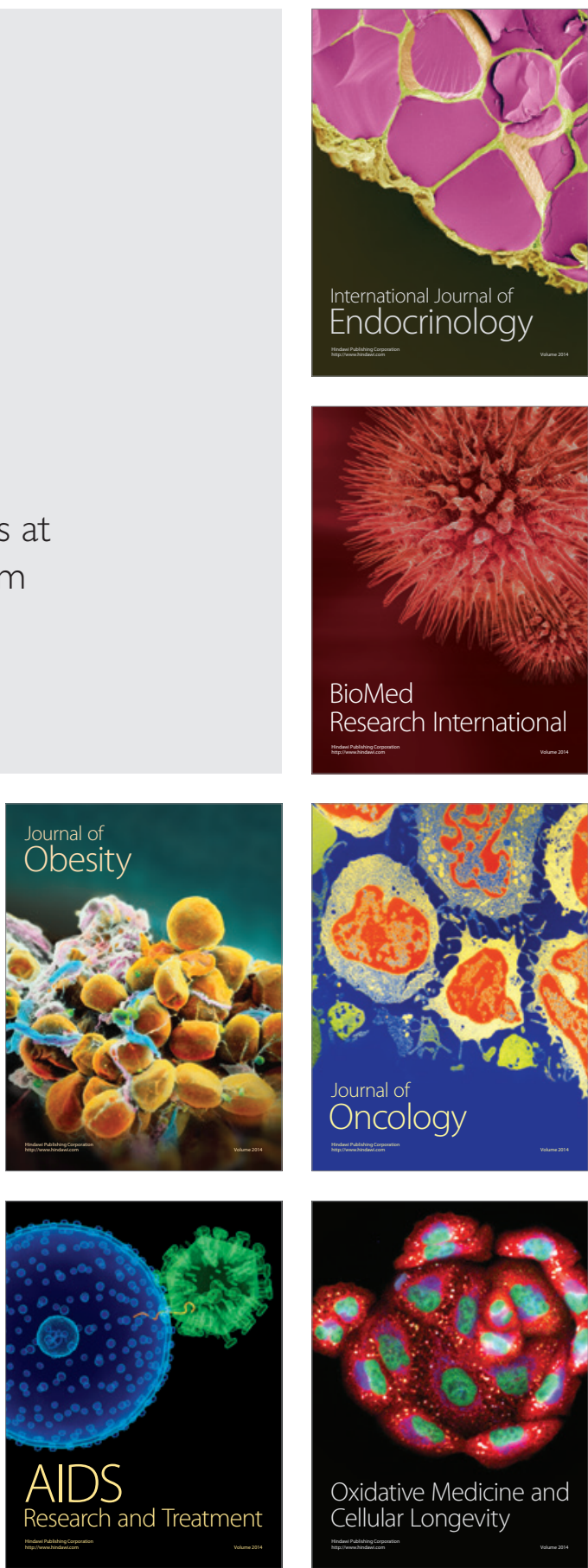